\title{
ESTIMATING BUS RUN TIMES FOR NEW LIMITED STOP SERVICE USING ARCHIVED AVL AND APC DATA
}

\author{
Paul R. Tétreault \\ Transportation planning and traffic \\ GENIVAR \\ 1600 René-Lévesque Blvd. W., 16th floor \\ Montréal, Québec, H3H 1P9 \\ Canada \\ Tel.: 514-343-0773 \\ Fax: 514-340-1337 \\ E-mail: paul.tetreault@mail.mcgill.ca
}

\author{
Ahmed M. El-Geneidy (corresponding author) \\ Assistant Professor \\ School of Urban Planning \\ McGill University \\ Suite 400, 815 Sherbrooke St. W. \\ Montréal, Québec, H3A 2K6 \\ Canada \\ Tel.: 514-398-8741 \\ Fax: 514-398-8376 \\ E-mail: ahmed.elgeneidy@mcgill.ca
}

Please cite as: Tétreault, P., \& El-Geneidy, A. (2010). Estimating bus run times for new limited-stop service using archived AVL and APC data. Transportation Research Part A: Policy and Practice, 44(6), 390-402. 


\section{INTRODUCTION}

In recent years, several transit agencies have been trying to be more competitive with the personal automobile to attract more choice riders. Transit agencies can only be competitive if they can provide services that are reliable (short wait time and less variation), have a short access and egress time, and have faster or comparable run times to automobiles. Transit agencies should also work towards increasing the satisfaction of their clients (Hensher \& Stanley, 2003). Revising the current distribution of service based on travel needs can increase the competitiveness of transit agencies. Improving run-time is an important measure, yet it has to be significant enough for users to be able to perceive changes in service (Ercolano, 1984). Implementing limited-stop service (express bus service) has proven to be one of the effective ways to reduce run time significantly and increase customer satisfaction (Conlon, Foote, O'Malley, \& Stuart, 2001).

In order to improve decision making and manage transit fleets, many transit agencies in North America and around the world have implemented automatic vehicle location (AVL) and automatic passenger counting (APC). These technologies can be used, among others, to improve route design and scheduling (Furth, Hemily, Muller, \& Strathman, 2003; Levinson, 2001). Yet they can also provide comprehensive information related to the state of existing services as well as the savings associated to changes in service through before and after analysis (Kimpel, Strathman, Bertini, Bender, \& Callas, 2005; Strathman, et al., 1999). 
The Société de transport de Montréal (STM), the transit agency providing service on the island of Montréal, Québec, Canada, is considering various measures to improve bus service. One such improvement is the introduction of limited-stop or express bus service that runs parallel to heavily used routes to improve run times for existing riders.

This paper focuses on using archived AVL and APC data obtained from route 67 Saint-Michel, a high frequency route, as well as origin destination survey data to select stops for implementing limited-stop bus service that will have the maximum impact on run time savings and minimum impact on passenger walking distances to bus stop. The archived data is used to generate various scenarios and to estimate run time savings along the new and the existing bus services. The paper starts with a literature review of bus run time and limited-stop service followed by a description of the studied route. The next section pertains to the methodology used to prepare and analyze the data for run time, select stops for limited-stop bus service and estimate bus run time for both new and existing bus service. It is then followed by a discussion of those results and finally a conclusion section.

\section{LITERATURE REVIEW}

When passengers choose to use transit as a mode of transportation, a number of factors come into account. Passengers want to have a reliable service that arrives on-time, with a minimum in-vehicle time (Murray \& Wu, 2003), and minimum access and egress time (Hensher, Stopher, \& Bullock, 2003). AVL and APC systems have been implemented by a number of transit agencies (Crout, 2007; Schweiger, 2003) and analyzed 
by a number of researchers with these goals in mind (Crout, 2007; El-Geneidy, Hourdos, \& Horning, 2009; El-Geneidy, Strathman, Kimpel, \& Crout, 2006; Strathman, Dueker, Kimpel, Gerhart, \& Callas, 2002). Furth at al. (2003) quantified some of the endless benefits of AVL and APC implementation in a comprehensive way, although neither of the two studies included designing scenarios for various modifications in the existing service.

\subsection{Run-Time}

Mohring, Schroeter and Wiboonchutikula (1987) estimated that passenger do value in vehicle time as $0.3-0.5$ of their wage. It is well known that in vehicle time is directly affected by run time. A number of factors have an influence on the run time. They can be divided into those that do not fall under the control of the transit agency, such as congestion or weather, and those that can be controlled by the agency such as route design and the behavior of drivers (Strathman \& Hopper, 1993). Nevertheless, operators can still account for uncontrollable factors through scheduling and "real-time corrective actions" (Strathman \& Hopper, 1993). Reducing mean travel times is beneficial for the transit operator and users (Feder, 1973). It reduces operating costs and the number of vehicles required. Minimization of travel time can thus attract new users to the system (Vuchic, 2005) and will greatly increase the overall customer satisfaction (Hensher, et al., 2003). In order to reduce travel times, various strategies have been advanced. Vuchic (2005) proposes various measures to increase the average speed of bus operations. These can be grouped into vehicle design, intersection design, stop placement and operational improvements. Levinson (1983) found that many factors influence the run time, but the reduction of the number of stops from 8 to 6 stops per mile leads to more time savings than 
eliminating the effects of congestion. The effect of reducing the number of stops is confirmed by other researchers as well (Abkowitz \& Engelstein, 1984; Bertini \& ElGeneidy, 2004; McKnight, Levinson, Ozbay, Kamga, \& Paaswell, 2003; Strathman, 2002; Strathman, et al., 2002). Strathman et al. (2002) also found that passenger demand increases run time but that the time consumed per passenger decreases as the passenger activity increases at the stop. Accordingly concentrating passenger activity in a smaller number of stops will also lead to more run time savings. The reduction in the number of stops can be achieved either by stop consolidation (El-Geneidy, et al., 2006) or by offering limited-stop or express bus service. A limited-stop service is expected to reduce run time for the new limited bus service as well as for the regular service running in parallel. The use of archived AVL and APC data can help in estimating the time savings from implementing limited-stop bus service, which we have not seen in the transit literature before.

\subsection{Limited-stop service}

Limited-stop or express bus service has been recommended as a measure to decrease travel times and the number of vehicles needed for service (Ercolano, 1984; Furth \& Day, 1985; Vuchic, 2005). Express or limited buses stop at only a few stops along a route while a parallel "local" or regular route serves all of the limited and intermediate stops. This can be contrasted with zonal service which makes all the stops in one zone and few or none in another (Vuchic, 2005). One of the drawbacks of express service is that wait times tend to increase after implementation (Furth \& Day, 1985), therefore they 
should be implemented parallel to high frequency routes (routes with short headways 8 of minutes or less) and high ridership routes. Ben-Akiva and Morikawa (2002) found that a high quality limited-stop or express bus service can be as attractive to users as a light rail service. Implementation of limited-stop bus service running parallel to an existing local service is seen as positive change by users. In Chicago users satisfaction increased for both limited-stop and local service after the introduction of the limited-stop service (Conlon, et al., 2001). To our knowledge, there are not any clear established criteria in the transit industry on how to select stops that will be served by new express service based on existing demand and transit performance. Previous studies regarding limited-stop service relied on mathematical formulations (Afanasiev \& Liberman, 1983) with little knowledge regarding existing demand, yet the savings were around 30\% in run time. The literature states that limited-stop service should be serving stops with high level of passenger demand (Crout, 2008; Vuchic, 2005). In terms of limited-stop service stop spacing, stops should be spaced several times greater than local stops (Vuchic, 2005), 800 to 1,600 meters apart (Conlon, et al., 2001; Furth \& Day, 1985; Silverman, Orosz, \& Zicklin, 1998) or 450 meters apart (Crout, 2008). This spacing contrasts with "local” bus stop spacing in urban areas which generally ranges from 200 to 600 meters (Ammons, 2001). It is also recommended that stops be located near transfer points and that they be paired with another stop in the opposite direction to avoid confusion for passengers (Crout, 2008). The dilemma when designing a new limited-stop service is that the objective should be to minimize travel times - Ercolano (1984) contends that user time savings need to be at least 
5 minutes in order for users to perceive improvements - while trying to maximize the use of the service.

\section{CASE STUDY}

Montréal is the second most populous metropolitan area in Canada with a population of 3.7 million. The STM operates bus and subway services on the island of Montréal which is home to about half of the region's inhabitants. Four subway lines served by 759 métro cars and 192 bus routes served by 1600 vehicles comprise the STM network which carries over a million trips per weekday. Route 67 is located to the east of downtown Montréal and runs North-South along a boulevard crossing through 5 boroughs within the City of Montréal. The route is $9.16 \mathrm{~km}$ long in the northbound direction and $9.96 \mathrm{~km}$ southbound. Line 67 connects to two métro (subway) stations at its southern terminus and another at its midway point. As such, it is one of the busiest surface routes in the city with an average ridership of 40,400 on weekdays. The built form around the route is mostly 3-storey triplexes mixed with some commercial buildings near major intersections. Table 1 includes a summary of route characteristics, while Figure 1 is a map of the studied route.

(Insert Table 1 around here)

(Insert Figure 1 around here) 
The experience with APC and AVL technology at the STM dates back to 1999. The current STM system is the third generation equipped on 220 buses out of 1,600 in the fleet. Buses equipped with APC and AVL are assigned to different routes to obtain a sample of bus operational information. Information is recorded at both the stop and trip levels by the system. This system is mostly used by the STM for revising schedules and generating performance measures such as schedule adherence.

\section{METHODOLOGY}

The objective of this paper is to develop a methodology to select stops for a limited-stop bus service and to estimate the run time of the new service through using archived AVL and APC data. AVL and APC data was obtained from a sample of trips serving route 67 . Over 273,000 individual stop records were obtained from the STM data archival system representing bus arrival and departure times at each stop along the route including information on passenger activity. The data was collected between August 27, 2007 and January 6, 2008. The records were cleaned in order to remove incomplete trips and recording errors. Analysis of this data was conducted at both the stop and trip levels.

The first step was to prepare summary tables and a run-time model to verify the quality of the data and identify if problems in the schedule do exist or not. After data cleaning and eliminating short-turn runs, 6620 trips were used for trip level run time analysis. The trip level analysis excluded data from the first and last stops in both directions. The second to last stop in the northbound direction also had to be removed from the analysis because layovers were often taken at this stop rather than the last 
scheduled stop. As such, the run time for this analysis was calculated from the departure at the second stop until the departure time at the last analysis stop (second last for southbound trips; third last for northbound trips). Most researchers agree on the basic factors affecting bus run times (Abkowitz \& Engelstein, 1983; Berkow, El-Geneidy, Bertini, \& Crout, 2009; Guenthner \& Sinha, 1983; Kimpel, et al., 2005; Levinson, 1983; Strathman, et al., 2002; Strathman, et al., 2000). Table 2 is a list of variables prepared for conducting the analysis.

(Insert table 2 around here)

In order to assess the robustness of the obtained AVL and APC data, a run-time model is established at the trip level. The model incorporates a number of variables relating to the time of day, bus type, delay and passenger activity as well as variables that to our knowledge have not yet been used. For example the variables accounting for the weather (Environment Canada, 2008) and separating the passenger activity by door. The following is the model specification used in the analysis:

(1) Run time = f(average load, passenger activity (boardings and alightings) at the front door, passenger activity at the front door squared, passenger activity at the back door, passenger activity at the back door squared, weekday trip, southbound trip, low-floor bus, early morning trip, AM peak trip, Midday trip, PM peak trip, number of actual stops, rain $(\mathrm{mm})$, snow fallen $(\mathrm{cm})$, snow on the ground $(\mathrm{cm})$, delay beginning of trip) 
In this model, the run time is expected to increase with passenger activity, for trips made on weekdays, for southbound trips, peak hour trips, with the delay at the beginning at the trip and with adverse weather conditions or the amount of snow on the ground. Trips served by low-floor buses and early morning trips are expected to be faster accordingly a negative coefficient is expected.

In order to design a limited-stop service we generated four scenarios. The first scenario kept only transfer stops (see figure 1). The second scenario selected the stops in the first quartile of passenger activity as measured by the APC counts. The third scenario used the Montréal origin-destination data for users of this route and selected the top quartile of stops with the most activity (Agence métropolitaine de transport, 2003). The Montréal origin-destination survey dates from 2003 and contains disaggregate information on travel behavior for $5 \%$ of the Montreal population. For transit users, it contains the sequence of transit routes that were used in a trip. The walking distance to the nearest limited-stop service in each scenario is calculated and compared to the current situation by using the street network to assess the effects of each scenario on walking distances.

Finally, a fourth scenario is generated to incorporate findings from the first three scenarios as well as recommendations derived from literature search and consultation with transit experts such as stop spacing. For example we selected 1 out of 4 stops to be included in the limited-stop service. This is based on the average spacing of stops on this route (250 meters) and the recommended spacing of 800 to 1,600 meters (Conlon, et al., 2001; Furth \& Day, 1985; Silverman, et al., 1998). 
To estimate the mean run time of the modified routes a model which divides passenger activity and actual stops between the stops served by the limited-stop service and those that are skipped by this service is generated. A separate model is generated for every scenario. It is expected that coefficients in these models will change slightly with each scenario. The general model is given below:

(2) Run time = f(average load, weekday trip, southbound trip, low-floor bus, early morning trip, AM peak trip, Midday trip, PM peak trip, number of actual stops, rain $(\mathrm{mm})$, snow fallen $(\mathrm{cm})$, snow on the ground $(\mathrm{cm})$, delay beginning of trip, actual stops at stops served by limited-stops, actual stops at skipped stops, front door boardings and alightings at stops served by limited-stop service, front door boardings and alightings at stops skipped, back door boardings and alightings at stops served by limited-stop service, front door boardings and alightings at skipped stops)

In the above model we are isolating the effects of passenger activity and actual stops made by the current service at skipped stops in order to estimate run time for the new limited-stop service and local service that will be running in parallel. Since estimating the actual number of passengers switching between regular and limited bus services is not possible a range of run time savings will be estimated. Three run times were estimated for each of the limited-stop service scenarios (estimate 1 through 3) and the regular service that will run in parallel. The estimated mean travel times are calculated by multiplying the coefficients obtained from the statistical models with the mean values of these variables 
(hereby referred to as time component). This method is known as sensitivity analysis and was used in previous transit research (El-Geneidy, et al., 2006).

For estimate 1 for the limited-stop service, which assumes a zero sum game, all passengers using the stops serving the limited-stop service in the current time will be switching to the new limited-stop service while the passengers using other stops will remain as customers for the regular service. This estimate is more of a realistic estimate (or best estimate). The limited-stop service run time is estimated through subtracting the time associated with front and back door passenger activity and the number of actual stops skipped from the mean run time of the current bus service that is derived from the statistical models. For estimate 1 for the regular service after the implementation of the limited-stop service, we subtract the time associated with passenger activity at the stops served by the limited-stop service from the mean run time derived from the statistical models in each scenario. This method assumes that all passengers at the stops not being served by the limited-stop service would use the regular service in the after period and all passengers at the stops being served by the limited-stop service would only use the new limited-stop bus service. As mentioned earlier, this method assumes a zero sum game among the number of passengers switching between stops when limited-stop service is offered.

For estimate 2 for the limited-stop service, which is more of an optimistic approach, run time estimate is derived without any passenger activity. The estimate 2 for the regular route would have the same average running time as the current route, since it assumes no passengers will move to the regular service. Although this is not real but it 
provides estimate of the maximum amount of savings for the limited-stop service as well as a minimum amount of savings or no change in the regular service after the implementation of the new limited-stop service.

For estimate 3 for the limited-stop service, which is more of pessimistic estimate in run time, all passenger activity along the existing route are estimated to switch to the new limited-stop service. This gives the minimum amount of savings that can be associated with this implementation. Run time is estimated by subtracting the coefficient associated with actual stops not being served by the limited-stop service from the current mean run time. For estimate 3 for the regular service it is more of an optimistic estimate where it assumes zero passenger activity and only incorporate values associated to time consumed at actual stops. This is the maximum amount of savings that the regular route can experience. Estimate 3 is similar to estimate 2 in term that it is not realistic. Yet it provides a minimum estimate for the limited-stop service where all the existing passengers will switch to it as well as a maximum estimate where there is complete decline in passenger activity along the regular service after the implementation of new limited-stop service.

\section{ANALYSIS}

The average run time along route 67 is just over 40 minutes which contrasts with the mean scheduled time of just under 39 minutes. For the analysis section, the pattern is similar: vehicles take longer to complete the route than is scheduled. This might be a 
problem in terms of schedule adherence if we also consider that the average bus leaves 48 seconds later than the scheduled departure. Summary statistics are reported in Table 3.

(Insert table 3 around here)

In terms of passenger activity, there is an average of 116 passengers using the front door while an average 48 passengers use the back door per trip. Because passenger activity outside the analysis segment for the trip was excluded, as would be expected, the number of passengers boarding and alighting does not add up in any trip. In average around 92 passengers will board a bus on an average trip, although the average load over the length of the trip is of less than 24 passengers. The mean number of actual stops in the analysis segment (30 out of 35 or 37 scheduled stops depending on route direction) suggests that limited-stop service might yield time savings. The high frequency of stopping is also a reflection of high passenger activity.

The average daily rainfall, snow and snow on the ground per trip during the study period were $1.46 \mathrm{~mm}, 0.84 \mathrm{~cm}$ and $6.9 \mathrm{~cm}$ respectively. The problem with these weather variables is that they vary considerably from their mean values. The extreme values suggest that certain weather events might have important impacts on travel time.

\subsection{Run-time model}

Since this is the first time that archived AVL and APC data obtained from the STM SCAD system is used for this type of analysis then developing a run-time model is an obvious way to assess the accuracy of this data. The characteristics of run time model are 
well known in the transit literature (Bertini \& El-Geneidy, 2004; El-Geneidy, et al., 2006; Levinson, 1983). Checking the effects of independent variables on run time and to what extent it follows the theory of transit planning is used as our benchmark for assessing the quality of the collected data. A general multivariate linear regression model for run time was derived using the archived trip data and is given in table 4.

\section{(Insert table 4 around here)}

As would be expected, the run time decreased (-2.34 seconds/passenger) as average passenger loads increased. This means drivers will go faster when having more passengers along the bus. This finding is similar to the finding from previous research (Dueker, Kimpel, Strathman, \& Callas, 2004). Passenger activity (boardings and alightings) at the front door increases the run time by 2.11 seconds per passenger, but since the activity at the front door squared is negative, the time per passenger decreased as the overall passenger activity increased. At the back door, each passenger activity decreases the run time by 0.99 seconds. This shows that use of the back door has a benefit on the run time, but since the passenger activity squared is positive, the time used by passenger increases as activity increases. The backdoor is generally used for alighting and the front is used for both boarding and alighting. Passenger activity at the backdoor occurs at the same time when passenger activity, mostly boarding, occurs at the front door. The negative value here is discounting the amount of time associated by passenger activity at the front door. Yet as it is clear from positive value of the square term this value is not the same for every passenger and the amount of savings decline when more passengers are using the backdoor 
till they are adding to the run time. The type of bus used for the route also has some benefits; low-floor buses are 98 seconds faster than high-floored buses if all other values are kept to their means. Weekday trips are longer by 39 seconds. Southbound trips are also longer by 151 seconds, which accounts for the additional distance, intersections and traffic signals. Time of day also has an important influence on run time. What is curious is that the coefficient associated with mid-day trips is greater than am peak trips. Of course, trips in the AM peak would still be longer when accounting for increased passenger activity, but this might be due to waiting at time points or other factors apart from traffic conditions. PM peak trips are much longer (180 seconds), probably due to the effects of congestion. The number of stops actually made also increases the run time and mostly accounts for deceleration and acceleration time (12.9 seconds per actual stop). Buses starting their runs late are faster than on time or ahead of schedule buses. Drivers seem to be adjusting their behavior based on whether they are ahead or behind schedule since run time decrease by 0.05 seconds for every second of departure delay. As Montréal is known for its severe winter conditions, the weather variables had a statistically significant impact on run time. For every millimeter of rain on a given day, the trip took an additional 1.81 seconds if all other values are kept to their mean. Snow also has an important impact on run time. For every centimeter of snow, the run time would increase by 2.87 seconds. The snow on the ground which accounts for lower temperatures and delays in snow clearing also has an impact on the travel time (2.26 seconds per centimeter of snow on the ground). The previous model shows us that it compares to previous research and can be used further for analysis which establishes the robustness of the STM data collection and archival 
system (Bertini \& El-Geneidy, 2004; El-Geneidy, et al., 2006; Furth \& Muller, 2007;

Kimpel, Strathman, Bertini, Bender, \& Callas, 2004; Levinson, 1983; Strathman, et al., 2002).

\subsection{Selection of stops for limited-stop service}

In scenario 1, all stops that are transfer points are selected for the limited-stop service. This scenario does not adjust for the frequency of intersecting routes. As can be seen in figure 1 , intersecting routes are numerous and are often clustered together, which will impose additional walking distances for users who would like to switch to this service. It is also clear from Figure 2 that passenger activity do vary as well at transfer points. Several of the transfer stops have low passenger activity, which will not support a successful implementation of a limited-stop service. This suggests that not all transfer points should be served by limited-stop service. Yet we developed this scenario based on a suggestion from theory and practice to show that just following the provision of limitedstop service at transfer points only is not the optimal solution.

Scenario 2 involved selecting stops based on passenger activity (alightings and boardings) at every stop along the route. A 1 in 4 ratio was used to select stops (i.e. the top 12 stops in terms of passenger activity along the route were selected). The 1 out of 4 ratio ensures a higher speed that can attract new riders and increase customer satisfaction. As can be seen in Figure 2, many stops selected in this scenario are in the middle of the route and have high passenger activity without being transfer points. The highest passenger 
activity, by far, was at métro stations as seen in the figure. In addition, not all transfer points have high passenger activity, which suggests that there would be less impact by excluding some transfer points. This scenario still has the disadvantage of having a few successive stops clustered together.

For the third scenario, data from users that declared that they used this bus route in the Montréal origin-destination is used. Trips from the OD survey are assigned to the transferring stop or the closest stop from their origin/destination based on whether users transferred from another route or walked to the route. A 1 in 4 ratio is also used to select the stops with the most passenger activity and the most origin-destination pairs. The advantage of using this survey is that we have approximate information on where passengers boarded and alighted the bus. This information is not revealed by the APC data. Using the stop selection in scenario 3, over 33\% of users would be able to board or alight at the same stop using the limited-stop service without having to transfer to the regular route or walk to the closest stop being served by the limited-stop service.

(Insert figure 2 around here)

As can be seen from the selection, using the APC/AVL data seems to be the best method to select stops, but all of these selection criteria are imperfect because they do not account for stop spacing. In scenario 4, we use both APC/AVL while trying to ensure an average spacing between 800 to 1,600 meters and keeping only 25\% of the existing stops in the new limited-stop service. The first criterion was the selection of stops that had the 
most activity. This led to the selection of major generators such as métro stations and important intersecting bus routes. After this initial criterion, stops were then selected in order to provide larger spacing and less clustering. The selected stops for scenario 4 are shown in Figure 3 along with scenarios 2 and 3.

(Insert figure 3 around here)

\subsection{Estimation of Bus Run Times}

The run time for each scenario is estimated based on the model presented in table 4 . Since it is difficult to give an exact run time, a range of travel times is given for both the limited-stop and regular services. These estimations assume that the route layout, traffic conditions and other conditions would remain unchanged. Three sets of travel times are estimated for each scenario. Estimate 1 is the realistic scenario for both the limited-stop service and the regular one. Estimate 2 is an optimistic scenario for the run time along the new limited-stop service and pessimistic scenario for the new regular service. Finally, estimate 3 is a pessimistic scenario for the run time along the new limited-stop service and optimistic scenario for the new regular service. The modified run time models separating passenger activity and actual stops into stops served by the limited-stop service and stops not served by this service are presented in table 5 . As can be seen, the magnitude of the coefficients has changed slightly when compared to the original run time model presented in table 4, yet the direction and statistical significance are around the same level in the model in table 5 except for the activity at the back door. 


\section{(Insert table 5 around here)}

By running separate run-time models for each scenario, we are capable of generating a matrix of run time estimates for the limited-stop and regular services. Table 6 shows the expected range of bus run times in the analysis segment. Scenario 4 would yield to the most time savings ( 4.5 to 8.6 minutes) because the coefficients associated to activity at stops skipped is higher and the average number of passengers and actual stops skipped is higher than any of the other scenarios. It is also important to note that although scenario 1 (time savings ranging from 3.6 to 7.7 minutes) serves twice as many stops, the run time is only roughly 1.5 minutes more when compared to scenario 4 . This is due to the fact that a large proportion of the time savings are associated with the actual stops skipped and with passenger activity. The time savings for scenarios 2 and 3 are almost the same (3.1 to 8.3 minutes and 3.2 to 8.3 minutes respectively). Selected stops in scenarios 2, 3 and 4 have the highest activity compared to scenario 1 stops. Since the activity squared terms were not included in this model, there might be additional time savings due to consolidating demand at certain stops.

\section{(Insert table 6 around here)}

Offering a limited-stop service should have an effect on passenger walking distances as well. Accordingly, it was important to measure the effects on walking distance associated with each scenario using the data from the O-D survey. Table 7 shows the average walking distance to the nearest stop served by the new limited-stop service. Scenario 4 has the advantage of having the smallest change in walking distances which 
would impact around $60 \%$ of users. This suggests that a number of users could walk to the next bus stop to access the limited-stop service.

(Insert table 7 around here)

Another way of looking at the effects of implementing the limited-stop service is magnifying the effects on personal travel time. Having the origin-destination survey enables estimating an average savings per person for current users. Looking at the people who boarded and alighted at one of the limited-stops in scenario 4, the expected time savings for passengers travel time using the estimate 2 (optimistic approach) is 2.3 minutes, while using the estimate 1 (realistic approach) is 1.5 minutes. It is important to note that these are passengers who are already using these stops before the limited-stop service is offered. The savings to passengers who might shift will be less since additional walking distances have to be taken into account. Yet these passengers might not need to shift since travel time savings are expected to occur along the regular route as well. Based on previous experience with implementation of limited-bus stop service user satisfaction is expected to increase (Conlon, et al., 2001).

Scenario 4 is recommended for implementation because of the time savings and the selection of stops accounted for various criteria including demand, transfer points, walking distances to stop and savings in travel time. Passengers who would not like to use the new service can still walk the current distance and use the regular service which STM is planning to retain. The savings from scenario 4 of limited-stop service should be implemented with other measures along the route such as stop consolidation (along the 
regular route), transit signal priority, exclusive bus lanes and adjusting the location of stops from near side to far side which could yield even more time savings for onboard passengers.

\section{CONCLUSION}

The objective of this research was to recommend a set of stops to be included in a new limited-stop service that will run parallel to a heavily used bus route in Montréal Canada and could yield substantial savings in run time for transit users. We used a new approach in order to estimate run times savings for various scenarios. A run time model based on current route conditions was derived from more than 6,000 trips. This run-time model at the trip level incorporated variables that accounted for the direction of the route, actual stops, time of day, type of day, delay at the first stop, passenger activity, and climatic conditions. To our knowledge, it is the first time that passenger activity by door and climatic conditions are used in run time models in transit operations and planning research. The activity through the back door shows that maximizing use of the back door can yield time savings. The model followed transit operations theory, which confirmed our confidence in the accuracy of the AVL and APC data obtained from the STM archival system. By separating passenger activity and number of actual stops between stops that are planned to be skipped as part of a new limited-stop service and stops that are proposed to be served by the regular service, we were able to estimate a range of mean run times. The recommended scenario (4) would yield time savings between 4.5 to 8.6 minutes for the limited-stop service for the analyzed route segment keeping all other operating 
conditions constant at their mean values. When we also consider the number of bus runs on this route per weekday, which is in excess of 350, this type of service can lead to considerable savings in operating time for the STM and travel time savings for users. By running a limited-stop service along this route, there would also be time savings for the regular route, though not as much as the limited-stop service, because part of the passenger activity would be shifted to the limited-stop service. For the recommended scenario, there could be savings over the segment analyzed of up to 4 minutes for the existing service.

The main contribution of this research is generating a methodology that depends on archived AVL and APC data to design a limited-stop service that target savings to the transit agency and users. The study also uses run time models in a unique way to generate estimates of run time savings for both the limited-stop service and the regular service. In addition changes in walking distances and in vehicle time are quantified for users using an OD survey. Previous research on limited-stop service depends mainly on mathematical formulations and is dated back to the 1980s with little dependence on existing demand and less understanding of passenger walking distances. Meanwhile, transit guidelines are limited to stop spacing when discussing limited-stop service. Finally, the run time estimations developed in this study were tested by the research team using a before-after study that was developed after the implementation of the limited stop service. The run time estimations developed in this paper fell in the acceptable range when compared to the real world situation after the implementation of the limited stop service (El-Geneidy \& Surprenant-Legault, 2010), which increase our confidence in the methodology developed. 
Future research for designing limited-stop service can also incorporate the variance in passenger activity as a factor. In this study, we did not have a large enough sample of trips beginning at the same time of day in order to evaluate the variance in passenger activity. STM is in the process of implementing the findings from this research. Accordingly, a post-implementation study will enable an accurate evaluation of the estimates proposed in this paper and the effectiveness of the final scenario in reducing run time along both routes (limited-stop and regular). In this study, we were concerned about the overall savings in run time along the studied route. A different approach is to use a smaller unit of analysis (stop-segment between time points) where other variables like number of signalized intersection can be incorporated in the model. This approach will enable modeling and estimating the effects of transit signal priority, which is planned as well to be part of this route.

Since the STM data is only a sample, accounting for headway deviations is not possible in this study. It is expected that headway deviations would have an effect on run time. In order to analyze this phenomenon, it would be necessary to have all buses serving this route equipped with AVL and APC technology. Finally, traffic condition variables are not available when conducting this analysis, the effect of congestion is partially accounted for through time of day and direction coefficients, obtaining such information can help in generating a better estimate. 


\section{ACKNOWLEDGEMENTS}

We would like to acknowledge the Société de transport de Montréal (STM) which provided funding and data for this project. This research was also partially funded by the Natural Science and Engineering Research Council of Canada (NSERC). In addition, we would also like to thank David Crout of TriMet for sharing TriMet’s standards for implementing limited-stop service. Last but not least, we would like to thank the anonymous reviewers for their feedback. 


\section{REFERENCES}

Abkowitz, M., \& Engelstein, I. (1983). Factors affecting running time on transit routes. Transportation Research Part A, 17(2), 107-113.

Abkowitz, M., \& Engelstein, I. (1984). Methods for maintaining transit service regularity. Transportation Research Record, 961, 1-8.

Afanasiev, L., \& Liberman, S. (1983). Principles for organizing express bus services. Transportation Research Part A, 17A(5), 343-346.

Agence métropolitaine de transport (2003). Enquête origine-destination 2003. Montréal, QC.

Ammons, D. N. (2001). Municipal benchmarks: Assessing local performance and establishing community standards (2nd ed.). Thousand Oaks, CA: Sage Publications.

Ben-Akiva, M., \& Morikawa, T. (2002). Comparing ridership attraction of rail and bus. Transport Policy, 9(2), 107-116.

Berkow, M., El-Geneidy, A., Bertini, R., \& Crout, D. (2009). Beyond generating transit performance measures: Visualizations and statistical analysis using historical data. Transportation Research Record(2111), 158-168.

Bertini, R., \& El-Geneidy, A. (2004). Modeling Schedule Recovery Processes in Transit Operations for Bus Arrival Time Prediction. Journal of Transportation Engineering, 130(1), 56-67.

Conlon, M., Foote, P., O'Malley, K., \& Stuart, D. (2001). Successful arterial street limited-stop express bus service in Chicago. Transportation Research Record, 1760, 74-80.

Crout, D. (2007). Accuracy and precision of TriMet's Transit Tracker system. Paper presented at the Transportation Research Board 86th Annual Meeting.

Crout, D. (2008). Express and limited services. In A. M. El-Geneidy (Ed.). Montreal. 
Dueker, K. J., Kimpel, T. J., Strathman, J. G., \& Callas, S. (2004). Determinants of Bus Dwell Time. Journal of Public Transportation, 7(1), 21-40.

El-Geneidy, A., Hourdos, J., \& Horning, J. (2009). Bus transit service planning and operations in a competitive environment. Journal of Public Transportation, 12(3), 39-59.

El-Geneidy, A., Strathman, J., Kimpel, T., \& Crout, D. (2006). The effects of bus stop consolidation on passenger activity and transit operations. Transportation Research Record(1971), 32-41.

El-Geneidy, A., \& Surprenant-Legault, J. (2010). Limited bus stop service: An evaluation of an implementation strategy. Paper presented at the Transportation Research Board 89th Annual Meeting, Washington DC, USA.

Environment Canada (2008). Climate Data Online Retrieved June 16, 2008, from http://www.climate.weatheroffice.ec.gc.ca/climateData/canada_e.html

Ercolano, J. M. (1984). Limited-Stop Bus Operations: An Evaluation. Transportation Research Record, 994, 24-29.

Feder, R. C. (1973). The Effect of Bus Stop Spacing and Location on Travel Time. Pittsburgh: Transportation Research Institute - Carnegie Mellon University.

Furth, P., \& Day, B. (1985). Transit routing and scheduling strategies for heavy demand corridors. Transportation Research Record, 1011, 23-26.

Furth, P., Hemily, B., Muller, T., \& Strathman, J. (2003). Uses of archived AVL-APC data to improve transit performance and management: Review and potential (TCRP Web Document No. H-28). Washington DC: Transportation Research Board.

Furth, P., \& Muller, T. (2007). Service reliability and optimal running time schedules. Paper presented at the Transportation Research Board 86th Annual Meeting. 
Guenthner, R. P., \& Sinha, K. C. (1983). Modeling bus delays due to passengers boardings and alightings. Transportation Research Record, 915, 7-13.

Hensher, D. A., \& Stanley, J. (2003). Performance-based quality contracts in bus service provision. Transportation Research Part A, 37, 519-538.

Hensher, D. A., Stopher, P., \& Bullock, P. (2003). Service quality-developing a service quality index in the provision of commercial bus contracts. Transportation Research Part A, 37, 499-517.

Kimpel, T., Strathman, J., Bertini, R., Bender, P., \& Callas, S. (2004). Analysis of transit signal priority using archived TriMet bus dispatch system data. Paper presented at the 84th Transportation Research Board Annual Meeting, Washington DC.

Kimpel, T., Strathman, J., Bertini, R., Bender, P., \& Callas, S. (2005). Analysis of transit signal priority using archived TriMet bus dispatch system data. Transportation Research Record(1925), 156-166.

Levinson, H. (1983). Analyzing transit travel time performance. Transportation Research Record, 915, 1-6.

Levinson, H. (2001). Bus transit in the 21st century some perspectives and prospects. Transportation Research Record, 1760, 42-46.

McKnight, C. E., Levinson, H. S., Ozbay, K., Kamga, C., \& Paaswell, R. E. (2003). Impact of Congestion on Bus Operations and Costs (No. FHWA-NJ-2003-008). Trenton, NJ: Region 2 University Transportation Research Center.

Mohring, H., Schroeter, J., \& Wiboonchutikula, P. (1987). The value of waiting time, travel time, and a seat on a bus. Rand Journal of Economics, 18(1), 40-56. 
Murray, A., \& Wu, X. (2003). Accessibility tradeoffs in public transit planning. [Article]. Journal of Geographical Systems, 5(1), 93-107.

Schweiger, C. L. (2003). Real-time bus arrival information systems. Washington, DC: Transportation Research Board.

Silverman, N., Orosz, T., \& Zicklin, A. (1998). Practitioner's Forum: Limited-Stop Bus Service at New York City Transit. Journal of Transportation Engineering, 124(6), 503-509.

Strathman, J. G. (2002). Tri-Met's experience with automatic passenger counter and automatic vehicle location systems. Portland OR: Center for Urban Studies, Portland State University.

Strathman, J. G., Dueker, K. J., Kimpel, T. J., Gerhart, R. L., \& Callas, S. (2002). Evaluation of transit operations: Data applications of Tri-Met's automated bus dispatching system. Transportation, 29, 321-345.

Strathman, J. G., Dueker, K. J., Kimpel, T. J., Gerhart, R. L., Turner, K., Taylor, P., et al. (2000). Service reliability impacts of computer-aided dispatching and automatic location technology: A Tri-Met case study. Transportation Quarterly, 54(3), 85-102.

Strathman, J. G., Dueker, K. J., Kimpel, T. J., Gerhart, R. L., Turner, K., Taylor, P., et al. (1999). Automated Bus Dispatching, Operations Control, and Service Reliability. Transportation Research Record, 1666, 28-36.

Strathman, J. G., \& Hopper, J. (1993). Empirical analysis of bus transit on-time performance. Transportation Research Part A, 27(2), 93-100.

Vuchic, V. (2005). Urban transit: Operations, planning and economics. Indianapolis, IN: John Wiley and Sons. 
